Article

\title{
Detection of Cassava Component in Sweet Potato Noodles by Real-Time Loop-mediated Isothermal Amplification (Real-time LAMP) Method
}

\author{
Deguo Wang ${ }^{1}$, Yongzhen Wang ${ }^{1}$, Kai Zhu ${ }^{1}$, Lijia Shi ${ }^{1}$, Meng Zhang ${ }^{1}$, Jianghan Yu ${ }^{1}$ and \\ Yanhong Liu ${ }^{2, *}$ (1) \\ 1 Key Laboratory of Biomarker Based Rapid-Detection Technology for Food Safety of Henan Province, \\ Xuchang University, Xuchang 461000, China; wangdg666@126.com (D.W.); wangdg666@aliyun.com (Y.W.); \\ 15649832270@163.com (K.Z.); shilijia19940908@163.com (L.S.); peterrabbit@yeah.net (M.Z.); \\ yjh18838466861@163.com (J.Y.) \\ 2 Molecular Characterization of Foodborne Pathogens Research Unit, Eastern Regional Research Center, \\ Agricultural Research Service, United States Department of Agriculture, Wyndmoor, PA 19038, USA \\ * Correspondence: yanhong.liu@ars.usda.gov; Tel.: +1-215-233-6587; Fax: +1-215-233-6581
}

Received: 4 May 2019; Accepted: 24 May 2019; Published: 29 May 2019

check for updates

\begin{abstract}
Sweet potato (Ipomoea batatas) noodles are a traditional Chinese food with a high nutritional value; however, starch adulteration is a big concern. The objective of this study was to develop a reliable method for the rapid detection of cassava (Manihot esculenta) components in sweet potato noodles to protect consumers from commercial adulteration. Five specific Loop-mediated Isothermal Amplification (LAMP) primers targeting the internal transcribed spacer (ITS) of cassava were designed, genomic DNA was extracted, the LAMP reaction system was optimized, and the specificity of the primers was verified with genomic DNA of cassava, Ipomoea batatas, Zea mays, and Solanum tuberosum; the detection limit was determined with a serial dilution of adulterated sweet potato starch with cassava starch, and the real-time LAMP method for the detection of the cassava-derived ingredient in sweet potato noodles was established. The results showed that the real-time LAMP method can accurately and specifically detect the cassava component in sweet potato noodles with a detection limit of $1 \%$. Furthermore, the LAMP assay was validated using commercial sweet potato noodle samples, and results showed that $57.7 \%$ of sweet potato noodle products (30/52) from retail markets were adulterated with cassava starch in China. This study provides a promising solution for facilitating the surveillance of the commercial adulteration of sweet potato noodles from retail markets.
\end{abstract}

Keywords: loop-mediated isothermal amplification (LAMP); adulterated sweet potato noodles; cassava-derived ingredients; internal transcribed spacer (ITS)

\section{Introduction}

Sweet potato (Ipomoea batatas) is a dicotyledonous plant that belongs to the family of Convolvulaceae. The roots of sweet potato are starchy, sweet-tasting, and tuberous vegetables. Sweet potato noodles are favored by many consumers due to this food's ease of cooking, good nutritional value, and easy digestion. There is a huge market for this food product in Asia, including China, Japan, and Korea. The food labels of noodle products are required to specify the starch source specifically to prevent adulteration and to protect consumers. However, the mixture of low-priced starch into high-priced starch is still very common. For example, cassava starch is often incorporated into sweet potato starch during the production of sweet potato noodles; therefore, a reliable method for the identification of starch species is critical for the surveillance of commercial adulteration [1]. 
At present, there have been some reports on the detection of starch adulteration, including methods based on physical properties (cohesiveness, extension, cutting behavior, cooking loss, and swelling index) and sensory evaluation [2], which are vulnerable to subjective factors. Methods based on near-infrared spectroscopy have a low sensitivity [3-7], and DNA-based methods such as Polymerase Chain Reaction (PCR) and DNA barcoding are very effective but rely on the requirements of professional skill and expensive instrumentation [8-11]. There is a need to develop a rapid, sensitive, and cost-effective method for the identification of adulterated starch, especially for sweet potato noodles processed at a high temperature.

Loop-mediated isothermal amplification (LAMP) has been developed to amplify nucleic acids under isothermal conditions, and it is a very specific, sensitive, and rapid technology [12]. The method has been reported to identify GMO maize starch [13]. The LAMP reaction is easily performed, and it is highly specific to the target sequence because six independent primes recognize the target sequence in the initial stage, and four independent primers are used to amplify the target sequence in the later stage of the LAMP reaction [14]. The amplification efficiency of the LAMP method is extremely high because it is an isothermal reaction with no ramp time for thermal change [15]. The objective of this study was to develop a reliable real-time LAMP method for the rapid detection of cassava-derived ingredients, to protect consumers from commercial adulteration. The most common material for sweet potato noodle fraud is starch of cassava (Manihot esculenta). In addition, the starch from Zea mays or Solanum tuberosum is sometimes used as the counterfeit material. The specificity of a newly developed real-time LAMP method for the rapid detection of cassava-derived ingredients was tested with starch from cassava (Manihot esculenta), Ipomoea batatas, Zea mays and Solanum tuberosum.

\section{Results}

\subsection{Primer Specificity for the LAMP Assay}

As shown in Figure 1, the length of the target sequences from Manihot esculenta was 193 bp. The identity of the sequences with the corresponding sequences of Ipomoea batatas (GenBank: MH792118.1), Zea mays (GenBank: KU182536.1), and Solanum tuberosum (GenBank: AY875827.1) was $79.91 \%$, blasted with DNAMAN (Lynnon Biosoft, San Ramon, USA); thus, the real-time LAMP assay using the cassava primers had a high specificity.
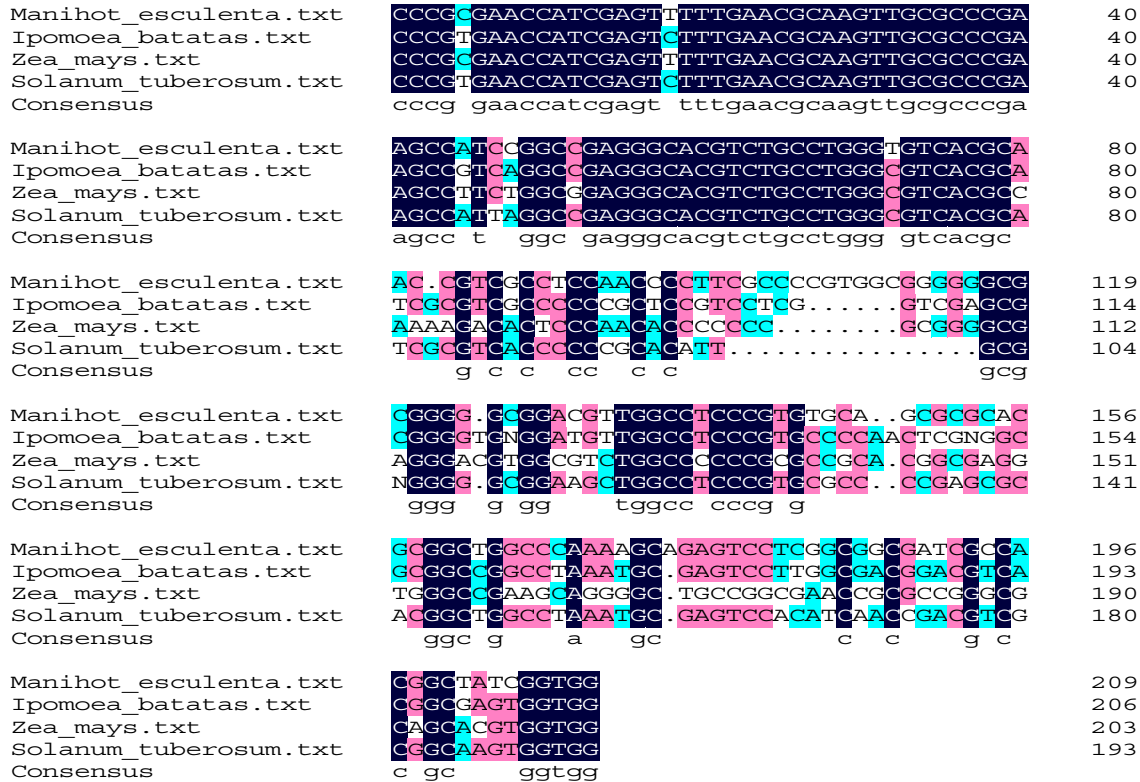

Figure 1. The alignment of the target sequences from Manihot esculenta with the corresponding sequences of Ipomoea batatas, Zea mays, and Solanum tuberosum. 


\subsection{Optimization of the Real-Time LAMP Reaction Temperature}

The LAMP reaction with the newly designed primers was carried out at $56{ }^{\circ} \mathrm{C}$ and $58{ }^{\circ} \mathrm{C}$ for $60 \mathrm{~min}$, and as shown in Figure 2, it resulted in the amplification of all positive controls (DNA from Manihot esculenta) along with negative results for all negative control (water only) reactions. Given the amplification efficiency and specificity, $58{ }^{\circ} \mathrm{C}$ was chosen as the most suitable reaction temperature.
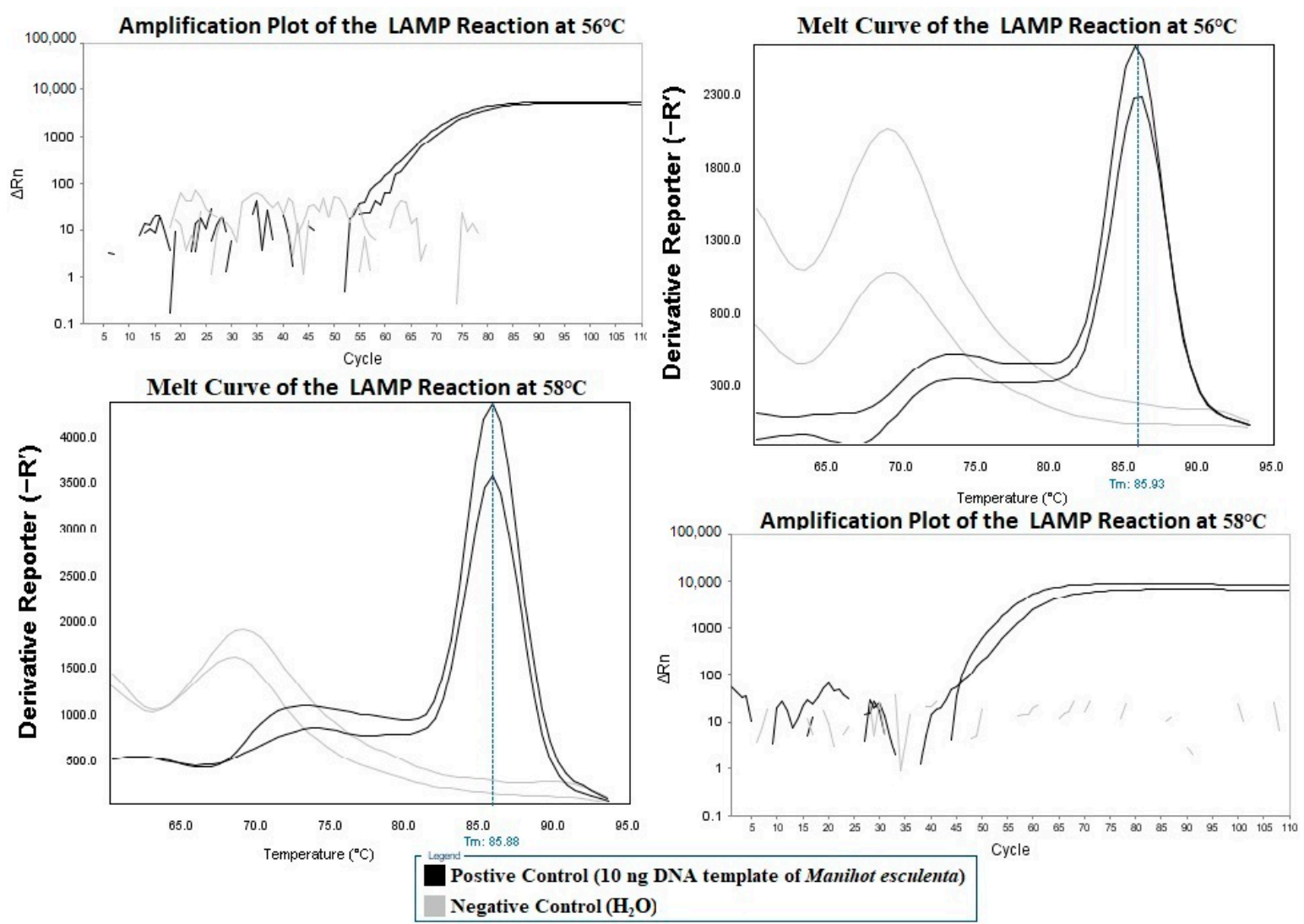

Figure 2. The LAMP reactions at $56{ }^{\circ} \mathrm{C}$ and $58{ }^{\circ} \mathrm{C}$.

\subsection{Specificity of the Real-Time LAMP Assay}

The specificity of the LAMP assay was tested with starch samples of Manihot esculenta, Ipomoea batatas, Zea mays, and Solanum tuberosum. The reason for this type of sample selection was that, alongside the most common material for sweet potato noodle fraud, starch from Zea mays or Solanum tuberosum is sometimes used as the counterfeit material. As shown in Figure 3, both cassava starch samples were successfully detected, while the starch samples from the other species were negative. 

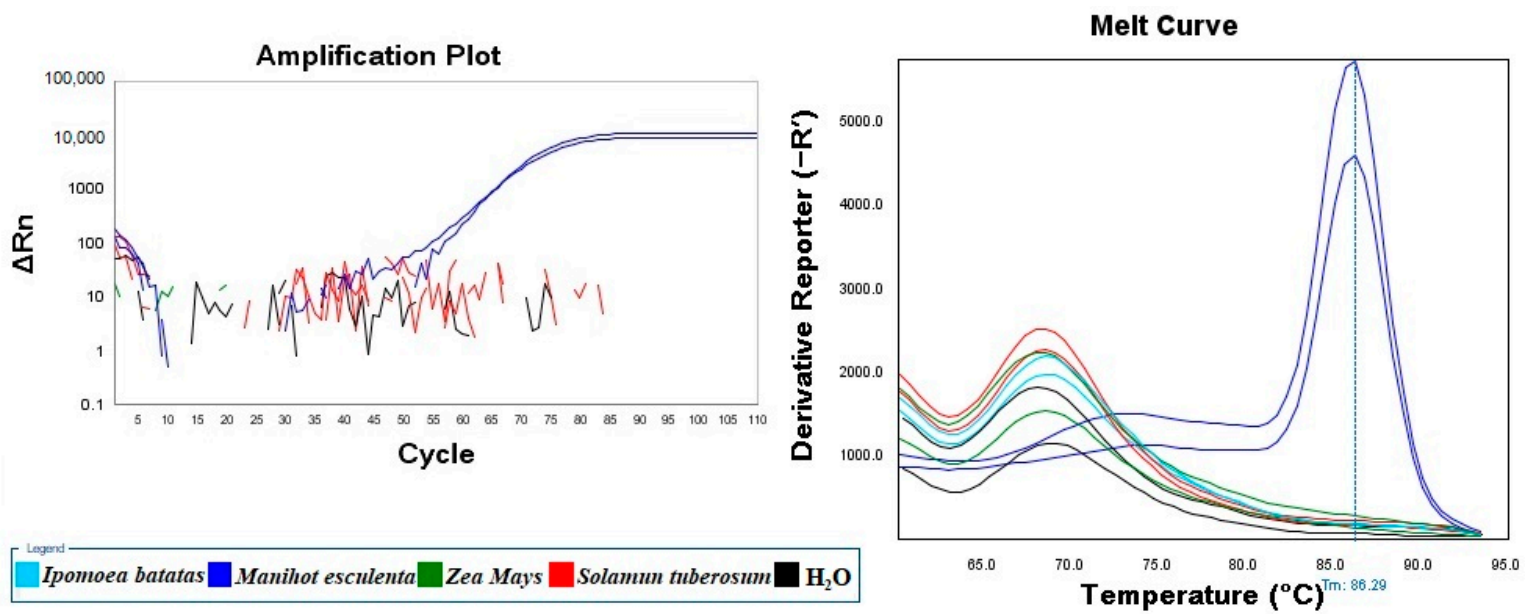

Figure 3. Specificity of the Real-time LAMP Assay.

\subsection{Sensitivity of the Real-Time LAMP Assay}

The sensitivity of the LAMP assay was determined with genomic DNA extracted from sweet potato starch mixed with different proportions of cassava starch at $58{ }^{\circ} \mathrm{C}$ for $60 \mathrm{~min}$. The detection limit was found to be the sweet potato starch mixed with $1 \%$ cassava starch, as shown in Figure 4 .

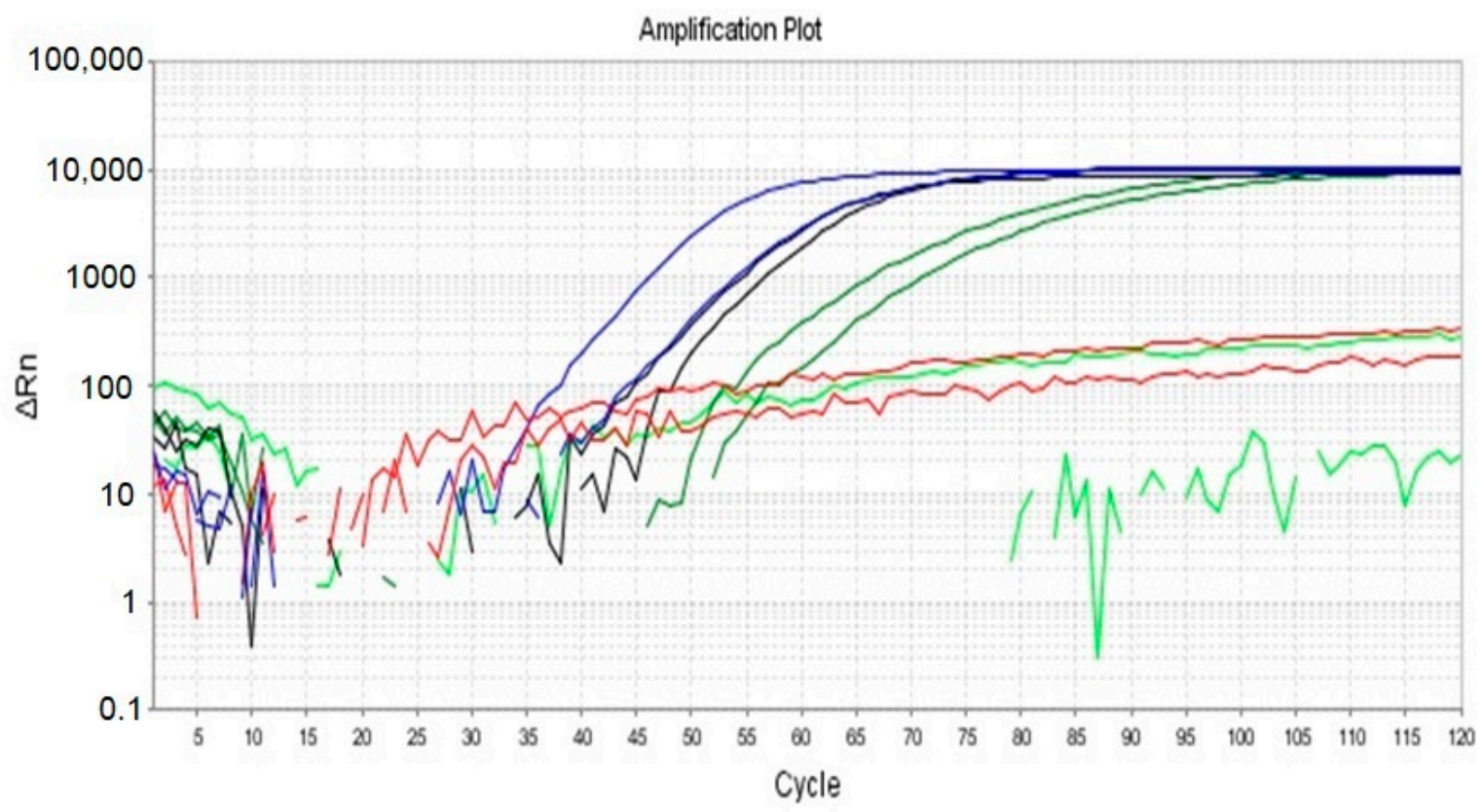

$5 \% \square \mathrm{H}_{2} \mathrm{O} \square 10 \% \square 1 \% \square 0.1 \%$

Figure 4. The detection limit of the real-time LAMP Assay. 10\%: DNA extracted from sweet potato starch containing 10\% cassava starch; 5\%: DNA extracted from sweet potato starch containing 5\% cassava starch; $1 \%$ : DNA extracted from sweet potato starch containing $1 \%$ cassava starch; and $0.1 \%$ : DNA extracted from sweet potato starch containing $0.1 \%$ cassava starch. 
2.5. Validation of the LAMP Assay for Detection of Cassava Starch Contamination of Sweet Potato Noodle Samples in China

Out of 52 sweet potato noodle samples collected from Chinese retail markets that were tested, 30 were found to be positive for cassava starch using the newly established real-time LAMP assay, indicating that fraud of sweet potato noodles with cassava starch may be very common in China.

\section{Discussion}

Since the LAMP technique was first reported in 2000 [12], researchers have explored its usage for analysis in various fields due to its excellent properties, including rapidity, sensitivity and specificity [16,17]; furthermore, the reports have been cited more than 5568 times, as listed by Google Scholar up to May 2019. The most notable advantage of LAMP is its rapidity, since LAMP can be performed in just $30 \mathrm{~min}$ because of the absence of a ramp time for thermal change [17,18]. The sensitivity of LAMP was not affected by the presence of non-target DNA in the samples, and the method was also more tolerant to well-known PCR inhibitors such as blood, serum and food ingredients [19]. LAMP has been developed to target various meat species, such as porcine, chicken, horse, and ostrich and had a sensitivity as low as $0.1 \mathrm{pg} / \mu \mathrm{L}$ [20]. The amplification specificity of LAMP was extremely high because the primers bind six independent sequences of the target DNA [15,19]. These properties made it attractive for us to explore the use of LAMP for the identification of sweet potato noodle adulteration.

Since starch contains a high carbohydrate content, and sweet potato starch was subjected to a heat treatment, it was difficult to extract enough high-quality genomic DNA from the noodles for the use of sweet potato noodle fraud testing with the DNA-based method. The improved CTAB method was used as the DNA extraction protocol in this study, and the internal transcribed spacer (ITS), with high copy number, was selected as the target sequence, significantly increasing the sensitivity and practicability of the newly established real-time LAMP assay.

There is no national standard or industry standard for sweet potato noodles in China, and the current national standard (GB/T 23587-2009 Vermicelli) does not have a method to distinguish noodles made of sweet potato starch from those made with low-cost cassava starch; consequently, sweet potato noodle fraud with cassava starch is very common in China. The adulteration of sweet potato noodles economically impacts sweet potato plantations and seriously impacts consumers. The advantages of the real-time LAMP assay are its cost-effectiveness, simplicity, high specificity and sensitivity, which make it suitable for the surveillance of commercial sweet potato noodle products that are adulterated with cassava starch.

\section{Materials and Methods}

\subsection{Primer Design for LAMP Assay}

A set of LAMP primers targeting the internal transcribed spacer (ITS) of Manihot esculenta (GenBank accession No. MK114629.1) were designed using PrimerExplorer V5 (http://primerexplorer.jp/e/) and Oligo 7 (Molecular Biology Insights, Inc. Colorado Springs, CO, USA). The primer sequences are listed in Table 1.

Table 1. LAMP primers from the Internal Transcribed Spacer (ITS) of Manihot esculenta.

\begin{tabular}{cc}
\hline Primer & Sequence $\left(\mathbf{5}^{\prime} \mathbf{- 3}^{\prime} \mathbf{)}\right.$ \\
\hline FIP & GGTTGCGTGACACCCAGGCATTTTACGCAAGTTGCGCCCG \\
BIP & GGACGTTGGCCTCCCGTGTTTTTCGCCGAGGACTCTGCTT \\
F3 & CCCGCGAACCATCGAGTT \\
B3 & ACCACCGATAGCCGTGG \\
LF & TCGGCCGGATGGCTT \\
\hline
\end{tabular}




\subsection{Genomic DNA Isolation}

Genomic DNA from the starch samples of Manihot esculenta, Ipomoea batatas, Zea mays, and Solanum tuberosum was extracted according to the method of Rajoo et al. [9]. Briefly, starch powders $(2 \mathrm{~g})$, homogenized with $10 \mathrm{~mL}$ of $3 \%$ cetyltrimethylammounium bromide (CTAB) buffer containing $0.3 \% \beta$-mercaptoethanol, were transferred to $50 \mathrm{~mL}$ tubes. After an incubation at $60{ }^{\circ} \mathrm{C}$ for $2 \mathrm{~h}$ with intermittent shaking, $3 \mathrm{~mL}$ of phenol: chloroform: isoamylalcohol (25:24:1) were added, mixed by inversion, and centrifuged at $8000 \times g$ for $15 \mathrm{~min}$ at $4{ }^{\circ} \mathrm{C}$. The aqueous phase was mixed with $7 \mathrm{~mL}$ of chloroform: isoamylalcohol (24:1) by inversion for $15 \mathrm{~min}$ and centrifuged at $8000 \times g$ for $15 \mathrm{~min}$ at $4{ }^{\circ} \mathrm{C}$. The aqueous phase was transferred to a fresh tube, and 0.6 volume of ice-cold isopropanol was added and incubated at $-20^{\circ} \mathrm{C}$ for $2 \mathrm{~h}$ to precipitate the DNA. After centrifugation at $4000 \times g$ for $5 \mathrm{~min}$, the pellets were washed with $70 \%$ ethanol, dried in the air and dissolved in sterile double distilled water. RNase was added to the DNA solution at a concentration of $10 \mathrm{mg} / \mathrm{mL}$, followed by incubation at $37^{\circ} \mathrm{C}$ for $1 \mathrm{~h}$. An equal volume of phenol: chloroform: isoamylalchohol (25:24:1) was added to the DNA solution, mixed for $15 \mathrm{~min}$, and centrifuged at $10,000 \times g$ for $15 \mathrm{~min}$ at $4{ }^{\circ} \mathrm{C}$. The aqueous phase was re-extracted for phenol. An equal volume of $100 \%$ ice-cold ethanol was added to the aqueous phase and incubated at $-20^{\circ} \mathrm{C}$ for $2 \mathrm{~h}$ to precipitate the DNA. After centrifugation at $4000 \times g$ for $5 \mathrm{~min}$, the pellets were washed with $70 \%$ ethanol to remove salts. The pellets were air dried and dissolved in $500 \mu \mathrm{L}$ double distilled water. Two hundred microliters of $30 \%$ PEG 8000 were added to $500 \mu \mathrm{L}$ of the DNA sample, mixed, incubated at room temperature for $30 \mathrm{~min}$, and centrifuged at $14,000 \times g$ for $15 \mathrm{~min}$. The pellets were washed with $80 \%$ ethanol, air-dried, and dissolved in nuclease free water or Tris-EDTA (10:1) buffer. The samples were frozen at $-20^{\circ} \mathrm{C}$ until further use. The noodle samples were homogenized using mortars and pestles before the DNA extraction.

\subsection{Optimization of Real-Time LAMP Reaction Temperature}

The real-time LAMP assay was performed in a $10-\mu \mathrm{L}$ reaction mixture containing $0.8 \mathrm{mM}$ each of forward inner primer (FIP) and backward inner primer (BIP), $0.2 \mathrm{mM}$ each of forward outer primer (F3) and backward outer primer (B3), $0.4 \mathrm{mM}$ of forward loop primer (LF), $1.0 \mathrm{mM}$ dNTPs, $20 \mathrm{mM}$ Tris- $\mathrm{HCl}$ (pH 8.8), $10 \mathrm{mM} \mathrm{KCl}, 10 \mathrm{mM}\left(\mathrm{NH}_{4}\right)_{2} \mathrm{SO}_{4}, 6 \mathrm{mM} \mathrm{MgSO}_{4}, 0.1 \%$ Triton X-100, 7.5\% DMSO [21], $1 \times$ EvaGreen, $1 \times$ Rox, $10 \mathrm{ng}$ DNA template of Manihot esculenta, and 3.2 U Bst 2.0 WarmStart DNA polymerase (New England Biolabs, Beverly, Mass., USA.) [22]. The reaction mixture was heated at $56^{\circ} \mathrm{C}$ or $58{ }^{\circ} \mathrm{C}$ for $60 \mathrm{~min}$ ( 30 s per cycle), and a melt curve was obtained using a StepOne ${ }^{\mathrm{TM}}$ System (Applied Biosystems, Foster City, CA, USA).

\subsection{Specificity Determination of the Real-Time LAMP Assay}

Genomic DNA of Manihot esculenta, Ipomoea batatas, Zea mays, and Solanum tuberosum was used for determining the specificity of our developed LAMP assay, and the amount of genomic DNA template used was $1 \mathrm{ng}$ per reaction.

\subsection{Sensitivity Determination of the Real-Time LAMP Assay}

The sweet potato starch was mixed proportionally with the cassava starch; the mass percent of cassava starch was $10 \%, 5 \%, 1 \%$, and $0.1 \%$, and genomic DNA was extracted according to the method of Rajoo et al. [9]. The detection limit was determined using the above real-time LAMP assay.

\subsection{Analysis of Sweet Potato Noodle Samples from Retail Markets}

A total of 52 samples labeled sweet potato noodles were collected from Chinese markets; the samples were homogenized, their DNA was extracted according to the method of Rajoo et al. [9], and the adulteration with the cassava component was tested with the real-time LAMP assay. 
Author Contributions: Y.W., K.Z., L.S., M.Z., J.Y. performed the experiments. D.W. wrote the paper. Y.L. and D.W. designed the experiments.

Funding: The research was funded by the National Key Research and Development Program of China, grant number 2016YFD0500704-4, and by Henan Science and Technology Plan Project, grant number 182102110285.

Acknowledgments: We would like to thank Pina M. Fratamico for critical reading of the manuscript.

Conflicts of Interest: The authors declare no competing interest.

\section{References}

1. Hong, E.; Lee, S.Y.; Jeong, J.Y.; Park, J.M.; Kim, B.H.; Kwon, K.; Chun, H.S. Modern analytical methods for the detection of food fraud and adulteration by food category. J. Sci. Food Agric. 2017, 97, 3877-3896. [CrossRef] [PubMed]

2. Chen, Z.; Sagis, L.; Legger, A.; Linssen, J.P.H.; Schols, H.A.; Voragen, A.G.J. Evaluation of starch noodles made from three typical Chinese sweet-potato starches. J. Food Sci. 2002, 67, 6. [CrossRef]

3. Ma, H.L.; Wang, J.W.; Chen, Y.J.; Cheng, J.L.; Lai, Z.T. Rapid authentication of starch adulterations in ultrafine granular powder of Shanyao by near-infrared spectroscopy coupled with chemometric methods. Food Chem. 2017, 215, 108-115. [CrossRef]

4. Lohumi, S.; Lee, S.; Lee, W.H.; Kim, M.S.; Mo, C.; Bae, H.; Cho, B.K. Detection of starch adulteration in onion powder by FT-NIR and FT-IR spectroscopy. J. Agric. Food Chem. 2014, 62, 9246-9251. [CrossRef]

5. Zhong, J.; Qin, X. Rapid Quantitative Analysis of corn starch adulteration in Konjac Glucomannan by chemometrics-assisted FT-NIR spectroscopy. Food Anal. Method 2016, 9, 61-67. [CrossRef]

6. Wang, N.N.; Shen, B.H.; Guan, J.J.; Zhao, Z.R.; Zhu, Y.W.; Zhang, L.D.; Yan, Y.L.; Zheng, Y.Y.; Dong, C.Y.; Kang, D.M.; et al. Detection of adulteration in milk powder with starch near infrared. Spectrosc. Spect. Anal. 2015, 35, 2141-2146.

7. Xu, L.; Shi, W.; Cai, C.B.; Zhong, W.; Tu, K. Rapid and nondestructive detection of multiple adulterants in kudzu starch by near infrared (NIR) spectroscopy and chemometrics. LWT Food Sci. Technol. 2015, 61, 590-595. [CrossRef]

8. Sasikumar, B.; Syamkumar, S.; Remya, R.; Zachariah, T.J. PCR Based Detection of Adulteration in the Market Samples of Turmeric Powder. Food Biotechnol. 2005, 18, 299-306. [CrossRef]

9. Rajoo, S.; Ahn, J.O.; Lee, H.W. Isolation and amplification of DNA from turmeric powder. Brit. Food J. 2004, 106, 673-678.

10. Dhanya, K.; Syamkumar, S.; Siju, S.; Sasikumar, B. Sequence characterized amplified region markers: A reliable tool for adulterant detection in turmeric powder. Food Res. Int. 2011, 44, 0-2895. [CrossRef]

11. Parvathy, V.A.; Swetha, V.P.; Sheeja, T.E.; Sasikumar, B. Detection of plant-based adulterants in turmeric powder using DNA barcoding. Pharm. Biol. 2015, 53, 1774-1779. [CrossRef] [PubMed]

12. Notomi, T.; Okayama, H.; Masubuchi, H.; Yonekawa, T.; Watanabe, K.; Amino, N.; Hase, T. Loop-mediated isothermal amplification of DNA. Nucleic Acids. Res. 2000, 28, e63. [CrossRef]

13. Zhen, Z.; Zhang, M.; Yu, Y.; Gao, X.; Zhu, Y.; Yan, Y.; Zhang, R. Establishment of a loop-mediated isothermal amplification (LAMP) detection method for genetically modified maize MON88017. Eur. Food Res. Technol. 2015, 242, 1-7. [CrossRef]

14. Wang, D.; Huo, G.; Ren, D.; Li, Y. Development and evaluation of a loop-mediated isothermal amplification (LAMP) method for detecting listeria monocytogenes in raw milk. J. Food Safety 2010, 30, 12. [CrossRef]

15. Wang, D.; Zhang, G.; Lu, C.; Deng, R.; Zhi, A.; Guo, J.; Zhao, D.; Xu, Z. Rapid Detection of Listeria monocytogenes in Raw Milk with Loop-Mediated Isothermal Amplification and Chemosensor. J. Food Sci. 2011, 76, M611-M615. [CrossRef]

16. Mori, Y.; Kanda, H.; Notomi, T. Loop-mediated isothermal amplification (LAMP): Recent progress in research and development. J. Infect Chemother. 2013, 19, 404-411. [CrossRef]

17. Wong, Y.P.; Othman, S.; Lau, Y.L.; Radu, S.; Chee, H.Y. Loop Mediated Isothermal Amplification (LAMP): A Versatile Technique for Detection of Microorganisms. J. Appl. Microbiol. 2017, 124, 626-643. [CrossRef] [PubMed]

18. Nagamine, K.; Hase, T.; Notomi, T. Accelerated reaction by loop-mediated isothermal amplification using loop primers. Mol. Cell Probes. 2002, 16, 223-229. [CrossRef] [PubMed] 
19. Zhang, X.; Lowe, S.B.; Gooding, J.J. Brief review of monitoring methods for loop-mediated isothermal amplification (LAMP). Biosens. Bioelectron 2014, 61, 491-499. [CrossRef] [PubMed]

20. Tasrip, N.A.; Khairil Mokhtar, N.F.; Hanapi, U.K.; Abdul Manaf, Y.N.; Ali, M.E.; Cheah, Y.K.; Mustafa, S.; Mohd Desa, M.N. Loop mediated isothermal amplification: A review on its application and strategy in animal species authentication of meat based food products. Int. Food Res. J. 2019, 26, 1-10.

21. Frackman, S.; Kobs, G.; Simpson, D.; Storts, D. Betaine and DMSO: Enhancing Agents for PCR. Promega. Notes 1998, 65, 27.

22. Wang, D. Novel primers for increased specificity and sensitivity for the detection of Staphylococcus aureus by Real-time LAMP. CYTA J. Food 2016, 14, 88-91. [CrossRef]

Sample Availability: Samples of the compounds are not available from the authors.

(C) 2019 by the authors. Licensee MDPI, Basel, Switzerland. This article is an open access article distributed under the terms and conditions of the Creative Commons Attribution (CC BY) license (http://creativecommons.org/licenses/by/4.0/). 